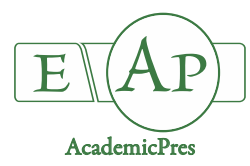

\title{
Favourable and Restrictive Factors for Quercus pubescens in the Transylvanian Basin, Evaluated by GIS Techniques
}

\author{
Vasile ȘIMONCA ${ }^{1,2}$, Sanda ROȘCA ${ }^{3 *}$, Alexandru COLIȘAR ${ }^{1}$, \\ Florin REBREAN ${ }^{1}$, Ștefan BILAȘCO ${ }^{3,4}$ \\ ${ }^{1}$ University of Agricultural Sciences and Veterinary Medicine Cluj-Napoca, Faculty of Horticulture, 3-5 Mănăştur Street, 400372, Cluj-Napoca, \\ Romania;simoncavasile@gmail.com; alexandrucolisar@gmail.com;florinrebrean88@gmail.com \\ ${ }^{2}$ National Institute for Research and Development in Forestry "Marin Drăcea", Cluj Collective Research, 65 Horea, Cluj-Napoca, Romania \\ ${ }^{3}$ Babeș Bolyai University, Faculty of Geography, Department of Physical and Technical Geography, 5-7 Clinicilor Street, 466664, Cluj-Napoca, \\ Romania; sanda.rosca@ubbcluj.ro (*correspondingauthor); stefan.bilasco@ubbcluj.ro \\ ${ }^{4}$ Romanian Academy Cluj-Napoca Branch Geography Section, 9 Republicii Street, 400015, Cluj-Napoca, Romania
}

\begin{abstract}
A very simple analysis of the forested areas across the Transylvanian Basin shows that they cover approximately $45.8 \%$ of the area, according to data provided by the European Environment Agency. In order to extend the areas covered by forests, especially over badlands specific for the Transylvanian Basin and to increase the economic and environmental value of these lands, a GIS model of spatial analysis has been developed to identify the areas favourable for downy oak (Quercus pubescens) plantations, a forest species which has specific requirements in terms of adaptability conditions. The developed spatial analysis model is based on the unitary analysis of the climatic, soil and geomorphologic components, spatially materialized as raster format databases, and their integration according to spatial analysis equations in order to get a modelled database which represents spatially the favourable areas for the creation of downy oak plantations. The result of this study highlights the territories which provide favourable but also restrictive conditions for Quercus pubescens. The model has a high predictability rate taking as comparative reference the direct monitoring at the level of forest planning units (PUs) within Cluj County, identified from the analysis of forestry plans. The high validation rate of the proposed model was obtained by overlapping the favourability classes which themselves were obtained after modelling with the limits of the forest planning units where the consistency of the downy oak is greater than 0.7 . According to the presented validation procedure, a $93 \%$ validation rate was obtained, fact which highlights the usefulness of applying the model in areas having similar features and its extrapolation in areas where the environmental conditions present only slight differences.
\end{abstract}

Keywords: ecological factors; downy oak; GIS modelling; interpolation

\section{Introduction}

The actual climatic changes identified both at global and regional level had a major impact, changing the vegetation generally and the forests particularly due to the gradual shift of the proper conditions for the development of certain forest species (Roșca et al., 2019).

The monitoring of changes in terms of land use and implicitly the expansion or reduction of forested areas may be indirectly performed on the basis of spatial analysis models which involve remote sensing techniques by means of integrated analyses of spectral bands within satellite images (Furtună, 2017; Mândru et al., 2018; Furtuna, 2017;
Roșca et al., 2019). Monitoring may also be directly performed by analysing the pre-processed spatial data provided by different monitoring agencies (European Environment Agency, Forestry Departments, the Agricultural Payment and Intervention Agency etc.).

The downy oak (Quercus pubescens) is a Mediterranean Central-European species that is native to Southern and Central Europe, Crimea and Anatolia. In the mountains surrounding the Mediterranean, it forms a specific level, the downy oak level (Pasta et al., 2016). In Romania, it forms smaller clumps, either pure or in association with other woodland species, more frequently in the Romanian Plain and almost entire Dobrudja and sporadically in Târnave Plateau, Someș Plateau and the Western Hills (Doniță et al., 1981). 
1300

It is an indigenous species of the third size, frequently the size of a shrub, with an often irregular and crooked stem. Many times, there are several specimens growing from almost the same place. The bark forms early a brown-black rhytidome, dense and deeply cracked, in somehow rectangular plates. The canopy is large and irregularly scattered, rare, allowing light, while the tendrils are ashypubescent, with alternative small buds, ovoid and rounded, tomentose. Unlike other oaks, the leaves are slightly downy (pubescent - with hairs) on the back side. The wood has good technological features, as it is similar to the Hungarian oak (Quercus frainetto), but is used only as firewood because of its small size (Ducousso and Bordacs, 2003; Arend et al., 2011; Wellstein and Cianfanglione, 2012).

It fructificates less and rather rarely, once in 5-7 years. This makes its regeneration very difficult. In years with weak fructification, the acorn of the downy oak is almost entirely destroyed by pernicious insects, mycotic diseases, rodents, wild boars and jay birds. But in the years with abundant fructification, the acorn is also destroyed in a percentage close to $90 \%$ by its pests, so the amount that remains is insufficient to ensure the natural regeneration from seeds (Florență, 2015).

Another cause for the difficulties met in the act of regeneration is either the steep slope of the hills they grow on $\left(35-40{ }^{\circ} \mathrm{C}\right)$ or the nature of the lithology. There are also anthropogenic threats, such as grazing near the trees or accidental fires (Guettouche and Derias, 2013; Bobiec et al., 2018).

The productive capacity of the downy oak is a low one. However, it has a high ecoprotective value in the forest steppe and in the area of low hills and plateaus, especially on the southern slopes, where the onset of other forest species is impossible or very difficult. For this reason, it is necessary to integrally preserve all the downy oak forests, as well as the existing clumps and groves outside the forest fund (Loidi and Herrera, 1990; Breda et al., 2006; Galiano et al., 2013).

In this study, the aim was to map the environmental factors - the climatic, geomorphological, soil and hydrological ones, which influence the distribution of the downy oak at the level of the Transylvanian Basin.

For this purpose, the GIS technology was used, allowing the spatial modelling of the determining ecological factors, acquired at point level by means of meteorological stations, soil cross-sections and diverse data retrieved scientifically. Previous studies underlined the utility of these methods due to the possibilities to use the raster and vector-type databases, to analyse the correlations established between the factors and to provide a quantitative model regarding the opportunities to use a certain species for afforestation, taking into account the restrictions and favourability induced by the environmental factors (Păcurar et al., 2013; Roșca et al., 2017; Roşca et al., 2019). The GIS technology is used both for the favourability study and for monitoring changes in forest vegetation (Lacaze et al., 1996; Rørstad et al., 2010; Furtună, 2017).

The regions where the downy oak covers a significant area may be allowed to become a natural protected area, a site of community importance, as an integral part of the European ecological network Natura 2000 in Romania. These areas have a high preservation value, taking into consideration that the Dacian forests of downy oak are found only sporadically in Romania, and sub Mediterranean species are also found in these areas. The tree layer consists mainly of downy oak (Quercus pubescens), while the herbaceous and shrub layers consist of typical forest and steppe species.

\section{Materials and Methods}

\section{Description of the study site}

The Corine Land Cover database, provided by the European Environment Agency by means of Copernicus programme, represents the most complete and highly accurate database which spatially represents land use classes and their changes in time. Based on the analysis of this database, it comes out that the forests covered approximately $5795.88 \mathrm{~km}^{2}$ across the Transylvanian Basin in 2012 (Fig. 1), which represents $45.8 \%$ of the entire area of the basin. In relation to the whole area covered by forests, $5617 \mathrm{~km}^{2}(98.4 \%)$ are covered by deciduous forests and only $64.35 \mathrm{~km}^{2}(0.55 \%)$ are covered by coniferous forests. The coniferous forests are located sporadically and mainly in the areas in close proximity to the Carpathian Mountains, surrounding the basin.

The other $114.13 \mathrm{~km}^{2}(0.98 \%)$ are covered by mixed forests. The need to stabilize the badlands highlights the importance of identifying the forest species that may properly adapt to areas affected by erosional processes. These species should belong to the class of deciduous trees which represents the most extended category in the analysed area. Based on direct analysis (field observation), it comes out that the species Quercus pubescens is not very sensitive to the temperature factor, which varies a lot across the Transylvanian Basin. This fact constituted the reason for performing this model to identify those areas which may be suitable for the analysed species.

\section{Implementation of the GIS model of spatial analysis}

The implementation of the GIS model of spatial analysis is based on a methodology developed according to the pursued goals. It is based on the digital databases managed by means of spatial analysis functions of geoinformation programmes and validated according to the comparison between the result and the territory. As such, three main stages may be identified. They observe the logic of model development, starting from the database acquisition in digital format (direct acquisition, acquisition based on spatial analysis submodels, and acquisition based on the implementation of interpolation functions), followed by the proper spatial analysis (based on qualitative scores and the implementation of spatial analysis equations) and ending normally with the model validation (direct comparison with the field reality (Fig. 2).

\section{Database acquisition}

The first stage in the methodological structure of the model is represented by the database acquisition. The base of the spatial analysis models is represented by the primary databases entering the model. They are directly acquired according to field measurements and their digital transposition by means of several techniques. 

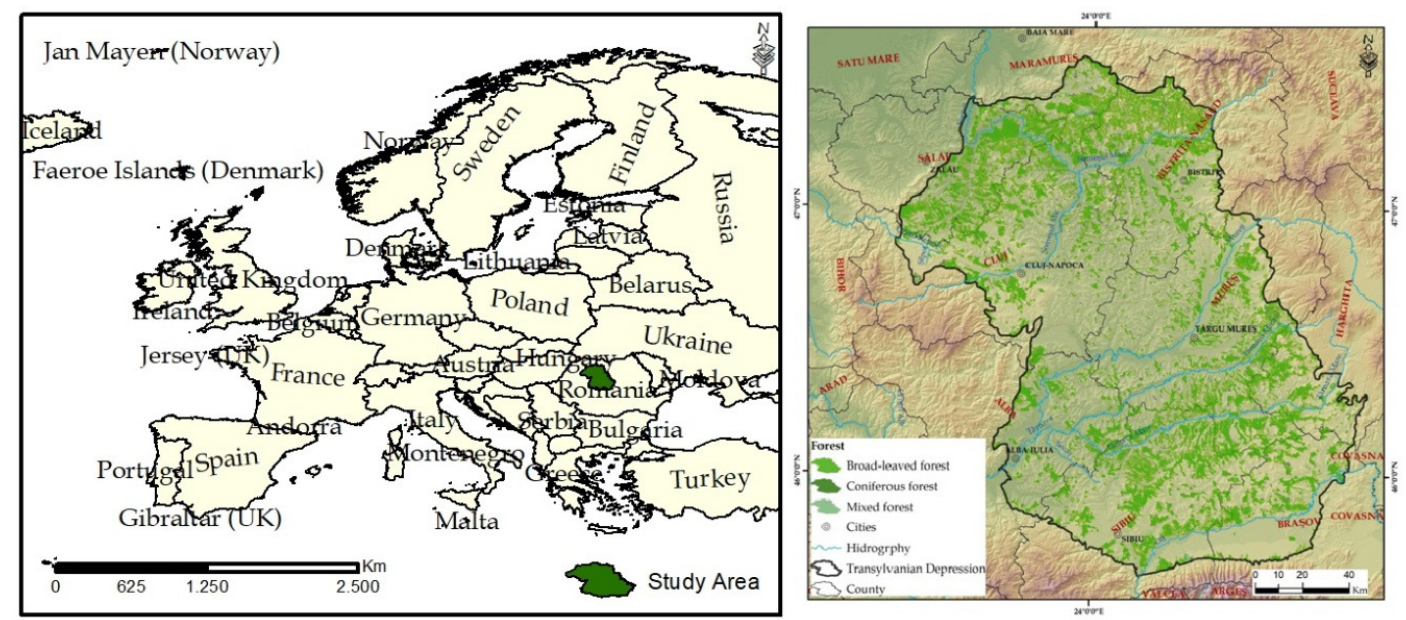

Fig. 1. Geographical position of the Transylvanian Basin, highlighting the areas covered by forests (according to Corine Land Cover, 2012)

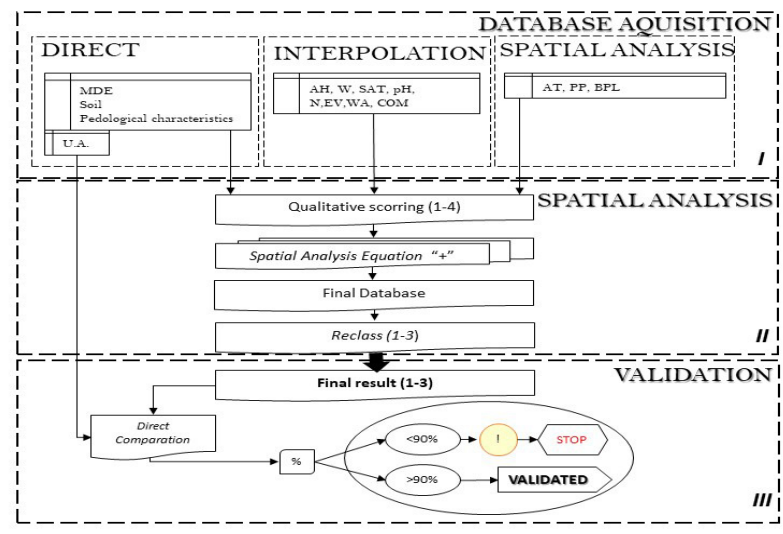

Fig. 2. Methodological flowchart

One of the most important techniques is the vectorization and the insertion of numerical and quantitative information in the attribute tables of the resulted vectors. The main database acquired directly by the described method is the one representing the point variation of the atmospheric humidity in the month of July, the wind speed, the degree of soil base saturation $(\mathrm{V} \%)$, the soil acidity, the $\mathrm{pH}$ in water, the nitrogen insurance (V. $0.01)$, the useful soil volume $\left(\mathrm{m}^{3} / \mathrm{m}^{2}\right)$. In the same category, of directly acquired databases, one may add the territorial coverage of soil types, their texture, the digital elevation model of the terrain (acquired by direct download from the internet, the SRTM model), as well as the administrative forestry units vectorized according to forestry plans.

A large part of the database acquisition which is basic for the model has been performed by means of derivation of spatial analysis submodels that have at their core the achievement of spatial correlations between their characteristic elements (average temperature, average amount of precipitation, length of bioactive period).

\section{Creation of digital spatial databases}

In order to finish the model, digital spatial databases have been created for a number of 14 factors (Table 1) considered being representative for the expansion of the downy oak habitat. They have also been included in the ecological file (Stănescu, 1979; Reif et al., 2017).
In the category of databases acquired on the basis of interpolation functions, one may include the raster databases acquired as a result of the territorial integration of quantitative numerical values attributed to point vectorial databases to estimate their values across areas without measurements. This punctual database regarding the locations of soil cross-sections and the geographical position of pluviometric and meteorological stations will be used in the interpolation process at the level of the whole area. The characteristic data for soils have been acquired from the 2014 Soil Survey, performed on $4 \times 4 \mathrm{~km}$ polygons, which is detailed enough for a regional study like this one. For this purpose, diverse interpolation functions (IDW and Kriging) have been used according to the statistical validation of the data sites to be interpolated.

\section{Implementation of the spatial analysis methods within the} model

The next stage was represented by the implementation of the spatial analysis methods within the model. The input elements are the spatial databases created in the previous stage. The first substage included within the spatial analysis is the qualitative scoring of the databases representing the 14 considered factors by means of reclassification according to the thresholds identified with the help of the ecological file. Therefore, values from 1 to 4 have been assigned, representing favourability classes: 1 - very low, 2 - low, 3 medium and 4 - high. The second substage within the spatial analysis stage is represented by the implementation of the spatial analysis equation on the basis of mathematical identifier " + " for the integration of the scored databases and the achievement of the final result -the identification of the areas with different degrees of favourability for Quercus pubescens. The spatial analysis equation was implemented in a GIS environment by means of ArcMap module and the raster calculator function, in the following manner:

$$
\text { " } A T+P P+B P L+A H+W+A L T+A S P+S A T+p H+N+
$$

$E V+W A+C O M+T E X T$ "

The result of the implementation of the spatial analysis equation materializes in a raster database which highlights the favourable or restrictive areas. This database needs to be reclassified, also within the spatial analysis process, having 
1302

the main goal of using it in the third stage, the model validation for the identification of its degree of representativeness. At the level of this database, one may then perform statistical inquiries regarding different degrees of favourability across different areas, such as administrative units like the counties or municipalities, or forest units.

\section{Model validation}

The model validation was performed in the third methodological stage. Initially, it involves the integration of two digital databases in different formats: the reclassified final result achieved as a consequence of the spatial analysis implementation (favourability or restrictiveness to Quercus pubescens) and a polygon-type vector database representing forest planning units, achieved as a result of direct acquisition. The integration of these databases has been performed by means of Statistical Analysis function of the ArcMap module. The main purpose was the identification of the overlapping degree of the existing areas with different degrees of favourability and restrictiveness. The model will be considered valid and applicable if the forest planning unit where Quercus pubescens has a consistence higher than 0.7 overlaps more than $90 \%$ with the class of high favourability. Otherwise, the model should be revised and recalibrated.

Table 1. Limits for favourable and restrictive factors for Quercus pubescens

\begin{tabular}{|c|c|c|c|c|c|}
\hline & \multirow{2}{*}{ Ecological factor } & \multicolumn{4}{|c|}{ Favourability for Quercus pubescens in the Transylvanian Basin } \\
\hline & & Very low (1) & Low $(2)$ & Medium (3) & High (4) \\
\hline 1. & Annual average temperature (AT) & $4.59-7$ & $7-8$ & $8-9.91$ & - \\
\hline 2. & $\begin{array}{l}\text { Annual average amount of precipitation } \\
\qquad(\mathrm{mm} / \text { year })(\mathrm{PP})\end{array}$ & $800-1044$ & $700-800$ & $603-700$ & - \\
\hline 3. & Bioactive period length (months) (BPL) & $3-6$ & - & - & - \\
\hline 4. & Relative atmospheric humidity - July (AH) & $70-81$ & $65-70$ & - & - \\
\hline 5. & Wind (Beaufort degrees) $(\mathrm{W})$ & $1,6,7,8$ & 5 & 2.3.4 & - \\
\hline 6. & Altitude (m) (ALT) & $800-1175$ & $600-800$ & $161-600$ & - \\
\hline 7. & Slope aspect (ASP) & $\begin{array}{c}\text { Shadow } \\
\text { Basins } \\
\text { Cold areas }\end{array}$ & Semi-shadow & $\begin{array}{c}\text { Sunny } \\
\text { Semi-sunny }\end{array}$ & - \\
\hline 8. & Base saturation degree (V\%) (SAT) & $<55$ & $55-75$ & $75-85$ & - \\
\hline 9. & Soil acidity ( $\mathrm{pH}$ in water) $(\mathrm{pH})$ & $4.8-6$ & $\begin{array}{c}6-6.4 \\
>7\end{array}$ & $6.4-7.2$ & - \\
\hline 10. & Nitrogen insurance (V. 0.01) (N) & $<1.5$ & $1.5-2$ & $>2$ & - \\
\hline 11. & Edaphic volume $\left(\mathrm{m}^{3} / \mathrm{m}^{2}\right)(\mathrm{EV})$ & - & $0.15-0.45$ & $>0.45$ & - \\
\hline 12. & Water supply capacity (\%) (WA) & - & $\mathrm{H} 3$ & $\mathrm{H} 0, \mathrm{H} 1, \mathrm{H} 2$ & - \\
\hline 13. & Soil compactness (COM) & - & $\begin{array}{l}\text { Very loose } \\
\text { Very compact }\end{array}$ & $\begin{array}{c}\text { Loose } \\
\text { Moderately } \\
\text { compact } \\
\text { compact }\end{array}$ & - \\
\hline 14. & Soil texture (TEXT) & - & $\begin{array}{c}\text { Sandy } \\
\text { Sandy-clayish } \\
\text { Loamy }\end{array}$ & $\begin{array}{l}\text { Clayish-sandy } \\
\text { Clayish } \\
\text { Clayish-loamy, } \\
\text { Loamy-clayish }\end{array}$ & - \\
\hline
\end{tabular}

\section{Results and Discussion}

Of all the species of oak, one finds that the downy oak is the most xerophytic and is also one of the species which enjoys a lot of light. However, it is very sensitive to late frost, fact explained by the presence of cracks (Ducousso and Bordacs, 2003). Therefore, for this reason, the downy oak covers usually the sunny upper and middle parts of the slopes, where the temperature is higher than in the lower parts. According to the studies made by Florență, 2015, the sum of the monthly average temperatures during the vegetation period totals $115^{\circ} \mathrm{C}$, while the same indicator for the Quercus pedunculiflora is $110^{\circ} \mathrm{C}$. The relatively small difference between the two species in terms of temperature demands is however sufficient to determine their certain vertical distribution.

As a result of the classification according to the favourability induced by the annual average temperature at the level of the Transylvanian Basin, which varies between 4.59 and $9.91^{\circ} \mathrm{C}$, one may notice that most of the basin area provides medium conditions for the development of the downy oak $\left(78.2 \%\right.$ of the area, or $\left.19822 \mathrm{~km}^{2}\right)$, where the annual average temperature is higher than $8^{\circ} \mathrm{C}$ (Fig. 3).

The areas with very low favourability in terms of temperature $\left(4.59-7^{\circ} \mathrm{C}\right.$ ) are located predominantly in the higher hills of the Transylvanian Sub Carpathians, covering an area of $536 \mathrm{~km}^{2}$ (2.12\% of the study area).

The annual average amount of precipitation varies between 603 and $1044 \mathrm{~mm} /$ year in the Transylvanian Basin. The lowest values are registered in the hilly areas of the Transylvanian Sub Carpathians, at the contact with the Carpathian Mountains. The sectors benefitting from an amount of annual precipitation between 603 and 700 $\mathrm{mm} /$ year provide the best conditions for the downy oak (only $32.4 \%$ of the study area, or $8232 \mathrm{~km}^{2}$ ). Most of the study area (59\%) provides a low favourability for the downy oak in terms of annual average amount of precipitation, as it 
ranges between 700 and $800 \mathrm{~mm} /$ year, and $7.9 \%$ has a very low favourability.

The wind speed is also a very important factor to consider when one needs to classify a territory in categories of favourability for a certain forest species. In this case, the largest part of the territory benefits from an average wind speed of $5.11-11 \mathrm{~km} /$ hour, which corresponds to a light breeze on Beaufort scale (Fig. 4). As a result of this classification, $99.4 \%$ of the territory may be included in the category of medium favourability for the downy oak.

The geomorphology, geology and the type of soil combined with the set of environmental factors temperature, light, humidity, etc., play a decisive part when the downy oak is in process of entering the vegetation period. Therefore, this also constitutes a limitative factor in the species distribution.

The altitude of the Transylvanian Basin ranges between 161 and $1175 \mathrm{~m}$. The areas located between 161 and $600 \mathrm{~m}$ high (representing $90.4 \%$ of the whole area) provides good conditions for the development of the downy oak. The other areas, located at altitudes higher than $600 \mathrm{~m}$, have a low or very low favourability for this species (Table 1, Fig. 4). Certainly, a high importance in the calculation of the temperature gradient is placed on determining the slope aspect. The slope aspect has a direct influence as a specific parameter that changes the amount of received solar radiation. Therefore, $46.7 \%$ of the study area belongs to the class of medium favourability (the case of sunny or semisunny slopes), $25.6 \%$ to the class of low favourability (for semi-shadowy slopes) and the remaining $27.5 \%$ to the class of very low favourability for the downy oak, as these areas are located on shadowy slopes.

From an ecological and edaphic point of view, the downy oak has a heterogeneous behavior. It grows well on levigated, neutral chernozems, heavier and drier than those populated by Quercus pedunculiflora, but it also appears sporadically in the hilly areas among pure sessile oak forests, or mixed forests made of sessile oak and spruce, up to altitudes of $550 \mathrm{~m}$ (for example, Ciuhii Hill near Sighişoara), on sunny slopes with dry soils formed on marls and limestones, which ensure the necessary heat.

According to the data acquired from the Romanian Soil Survey, the soil base saturation varies ranges between 55 and $85 \%$. The classification of the Transylvanian Basin on favourability classes for the downy oak, induced by the soil base saturation degree, highlights that $60 \%$ of the territory belongs to low favourability class (for base saturation values between 55 and 75\%). The best (most favourable) areas for the downy oak are found across $36.2 \%$ of the study area, where the base saturation value is higher than $75 \%$ (Fig. 5).

The soil acidity was determined according to the $\mathrm{pH}$ in water and has values between 4.8 and 7.2. the areas characterized by values between 6.4 and 7.2 provide the best conditions for the downy oak, but they cover only $28 \%$ of the whole study area. The remaining $61.4 \%$ is represented by the class of low favourability and $9.9 \%$ by the class of very low favourability (Fig. 6). The soil nitrogen insurance provides a medium favourability for $76.5 \%$ of the Transylvanian Basin, including those areas characterized by values higher than 2 (V.0.01). Areas characterized by values smaller than $1.5(1.77 \%)$ provide a very low favourability, while those characterized by values between 1.5 and 2 represent $21.6 \%$ and have a low favourability for the downy oak (Fig. 6). The useful edaphic volume (Fig. 7) have values ranging between 0.23 and $1.5 \mathrm{~m}^{3} / \mathrm{m}^{2}$, meaning that they provide a medium favourability for the downy oak across almost the entire Transylvanian Basin (98\%).

The implementation of the GIS spatial analysis model supposes the integration of all databases representing the favourable and restrictive factors for the downy oak, classified with score values from 1 to 4 by means of the spatial analysis equation which completes the proposed model. The equation is implemented according to the methodology proposed in this study, involving the sum of all determining ecological factors, weighted as having an equal influence in the final result. As a consequence of the implementation of the spatial analysis equation, areas with different favourability degrees, classified from 1 to 3 ( 1 for the very low favourability class, 2 for the low favourability class and 3 for the medium favourability class) have been achieved in the digital databases. One remarks the absence of the high favourability class, which has not been identified across the analysed territory once the model was complete (Fig. 8).

Therefore, taking into account the climatic, soil and morphological conditions of the Transylvanian Basin, one remarks that on $8424 \mathrm{~km}^{2}$ (34.4\% of the territory) there are good conditions for the development of the downy oak. The largest areas with such conditions are located in the counties of Sibiu $\left(2275.4 \mathrm{~km}^{2}\right)$, Mures $\left(1893.8 \mathrm{~km}^{2}\right)$ and Alba $\left(1600 \mathrm{~km}^{2}\right.$ ) (Table 2). Most of the territory (15058 $\mathrm{km}^{2}$, representing $61.45 \%$ ) is included in the low favourability class and the remaining $1022 \mathrm{~km}^{2}$, representing only $4.17 \%$ of the whole study area, in the very low favourability class (Fig. 9).

Table 2 . The favourability classes by counties of the Transylvanian Basin

\begin{tabular}{|c|c|c|c|c|}
\hline \multirow{2}{*}{ No } & \multirow{2}{*}{ County } & \multicolumn{3}{|c|}{ Favourability classes $\left(\mathrm{km}^{2}\right)$} \\
\hline & & Very Low & Low & Medium \\
\hline 1 & Alba & 0.4 & 646.5 & 1600.3 \\
\hline 2 & Bistrița-Năsăud & 444.2 & 2129.3 & 588.0 \\
\hline 3 & Braşov & 75.3 & 1289.0 & 554.7 \\
\hline 4 & Cluj & 124.7 & 3614.3 & 991.9 \\
\hline 5 & Harghita & 73.6 & 968.5 & 165.4 \\
\hline 6 & Maramureş & 115.2 & 493.6 & 32.1 \\
\hline 7 & Mureş & 166.2 & 3008.3 & 1893.8 \\
\hline 8 & Sălaj & 8.6 & 1481.4 & 322.7 \\
\hline \multirow[t]{2}{*}{9} & Sibiu & 14.0 & 1427.9 & 2275.4 \\
\hline & Total & 1022.2 & 15058.7 & 8424.3 \\
\hline
\end{tabular}


1304
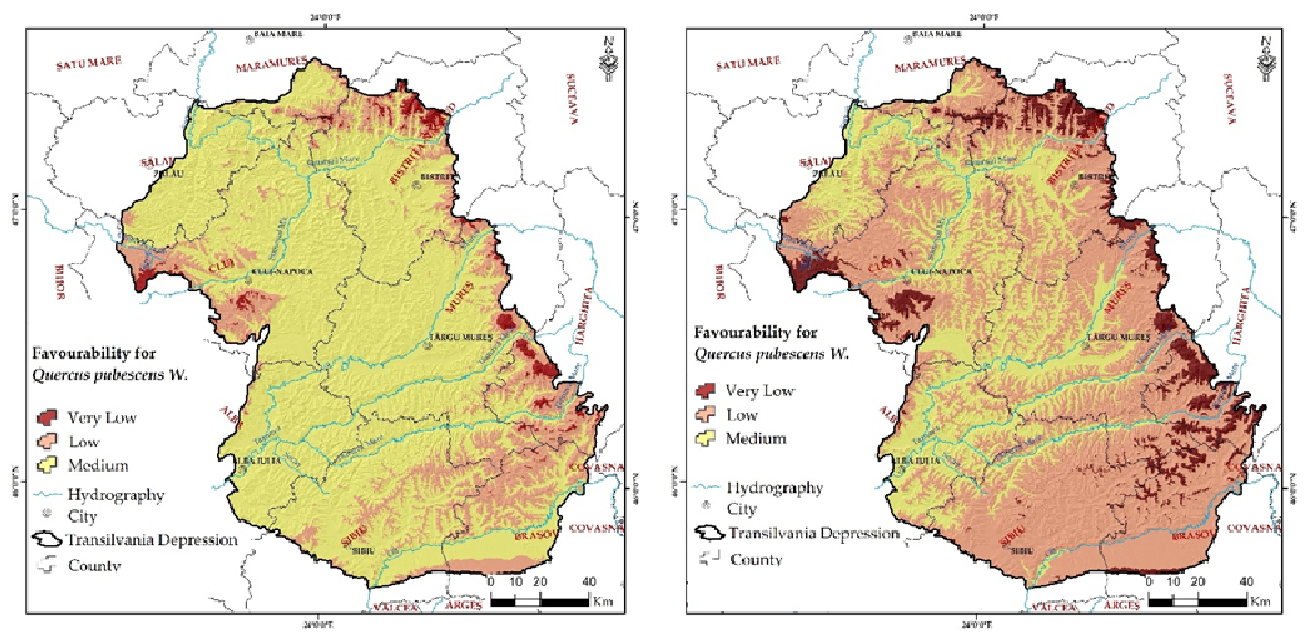

Fig. 3. Favourability for $Q$. pubescens in terms of annual average temperature (left) and the annual average amount of precipitation (right)
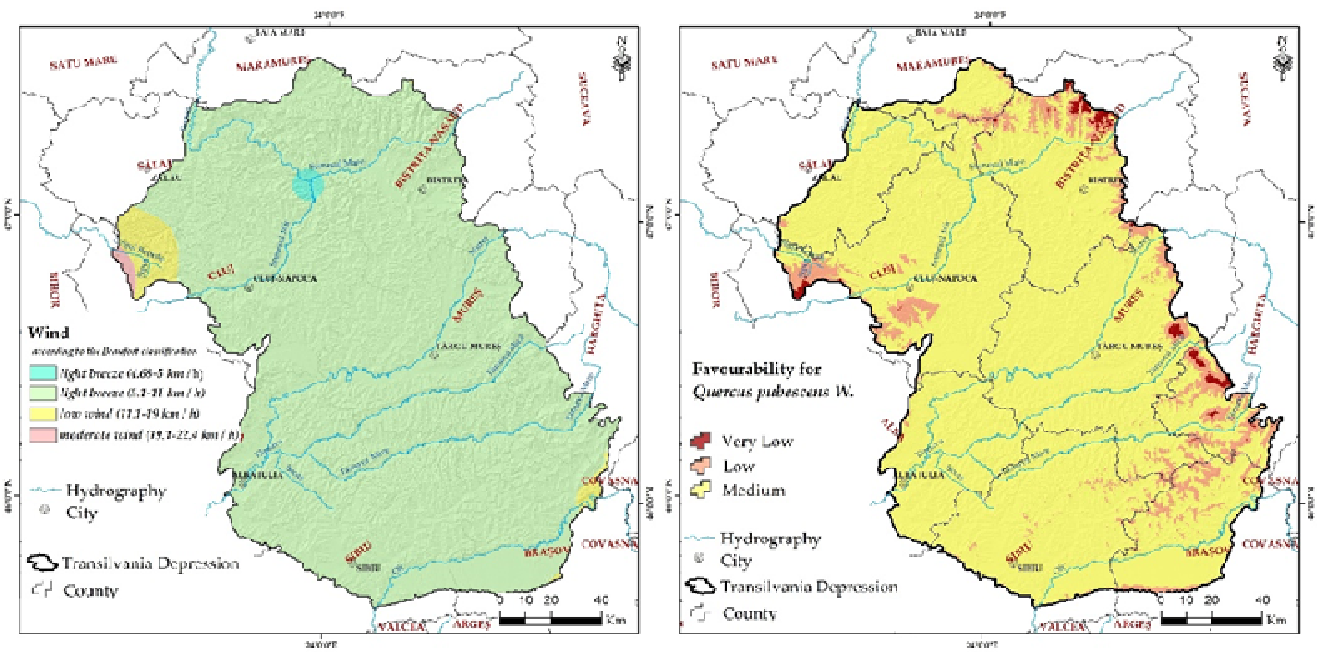

Fig. 4. Favourability for Q. pubescens according to wind speed (left) and altitude (right)
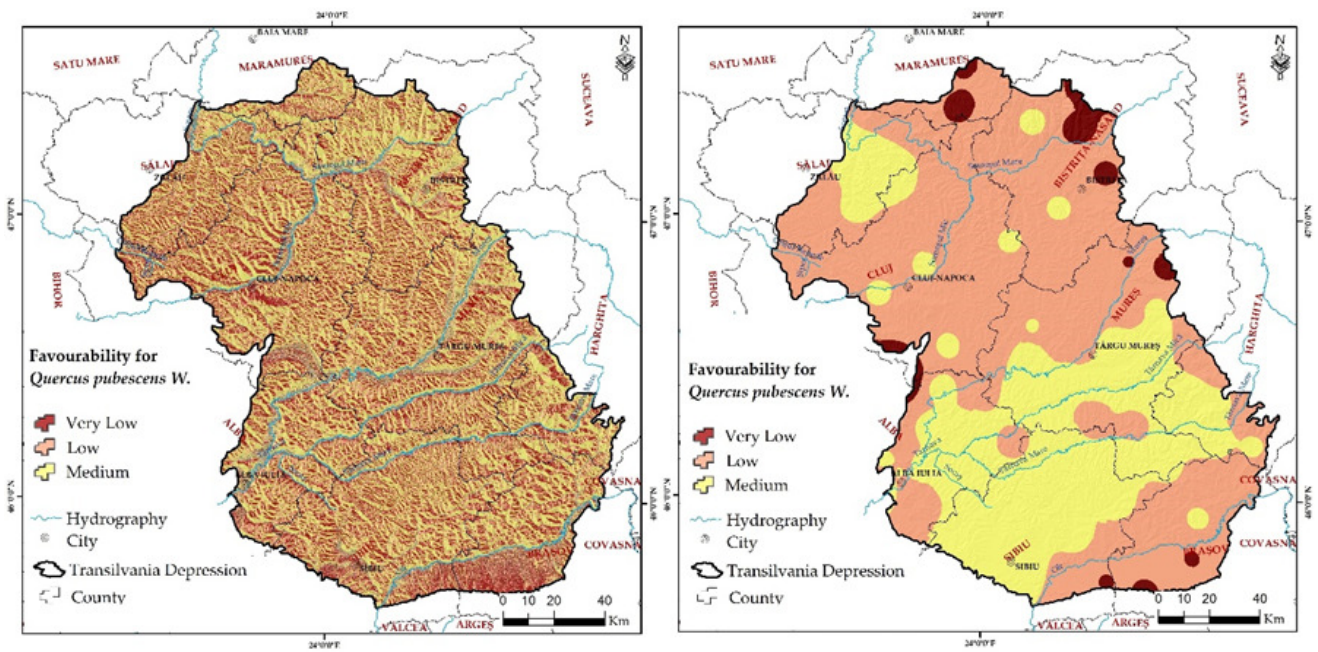

Fig. 5. Favourability for Q. pubescens according to slope aspect (left) and soil base saturation (right) 

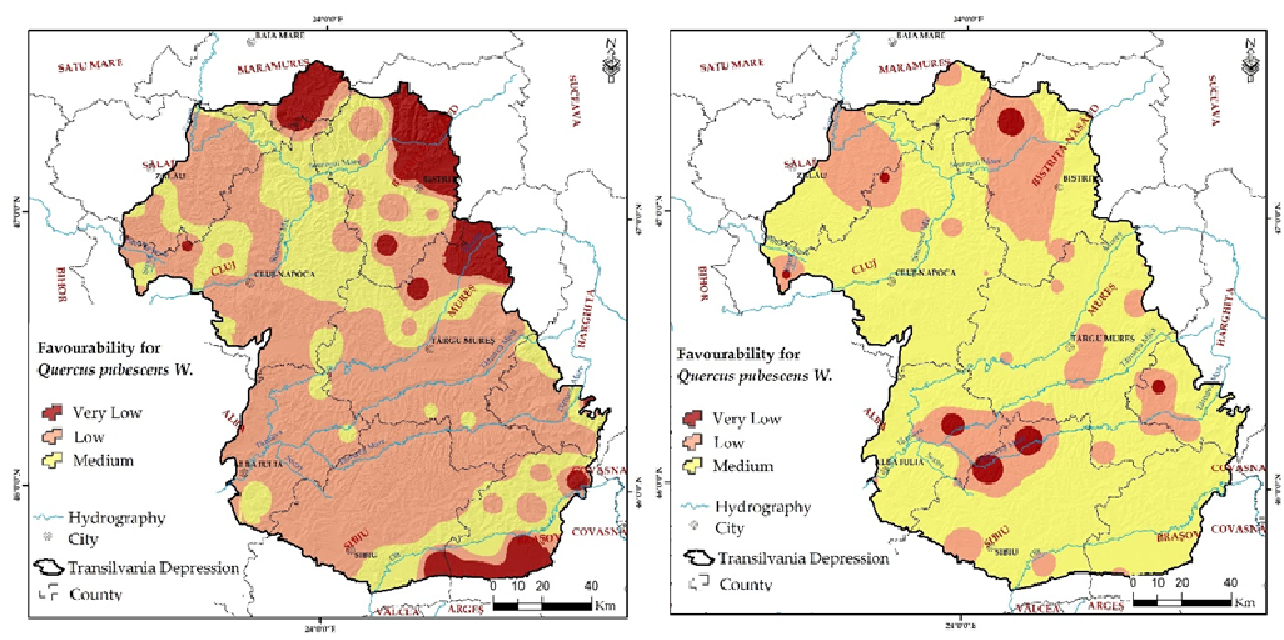

Fig. 6. Favourability for Q. pubescens according to soil acidity (left) and nitrogen insurance (right)
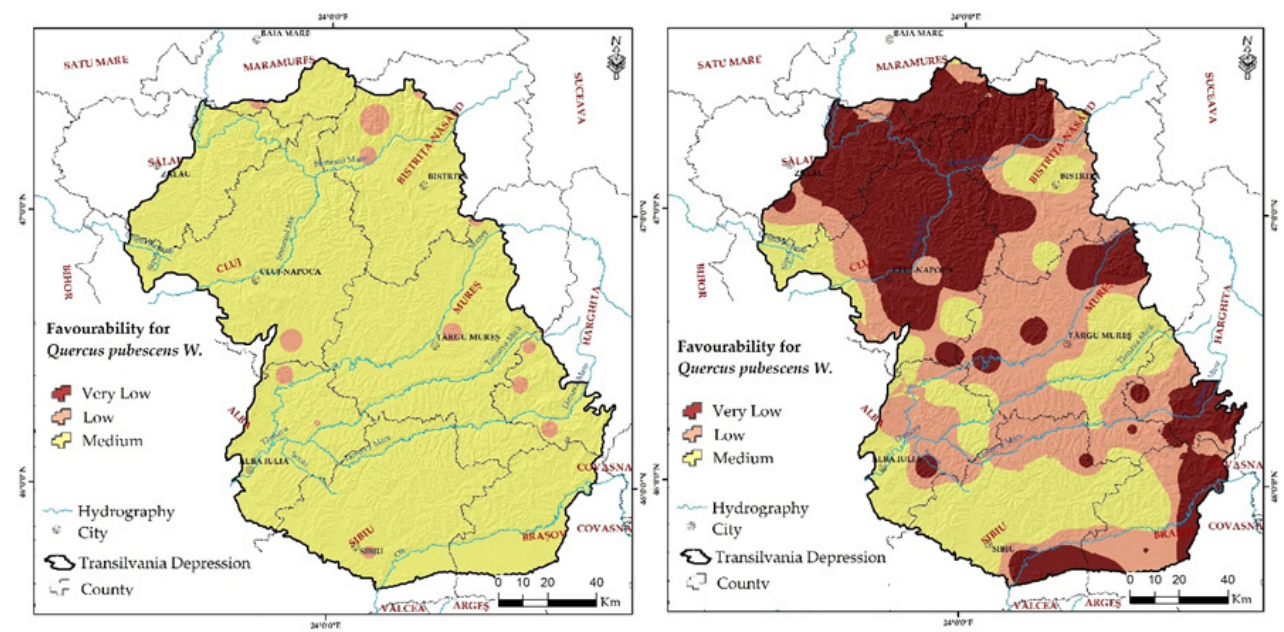

Fig. 7. Favourability for Q. pubescens according to the useful edaphic volume (left) and the water supply capacity (right)

The model validation having the main purpose of identifying its rate of success has been performed by comparing directly the final result with the reality in the field. In order to perform the validation according to the proposed methodology, vectorial databases representing existing areas within planning units of Gherla Forest Administration (planning units 35a, 36a, 88, 88b, 92a, 93b and 100) have been directly acquired by digitization. In these planning units, the downy oak (Quercus pubescens) has a consistence higher than 0.7. One remarks that none of the areas where the downy oak has been identified are included in the class of very low favourability. The forest planning units $93 \mathrm{~b}$ and 100 are entirely included in the medium favourability class (Fig. 9). As a result of achieving the model validation by using the proposed method, a $93 \%$ validation rate has been obtained, which highlights the correct approach concerning the drawing up of primary databases and the correct methodology proposed as basis for the spatial analysis. Therefore, one proposes the implementation of the model across the analyzed territory, with the main purpose of helping decisions to be made when there are afforestation proposals involving new species, adapted to the present climatic and environmental conditions.
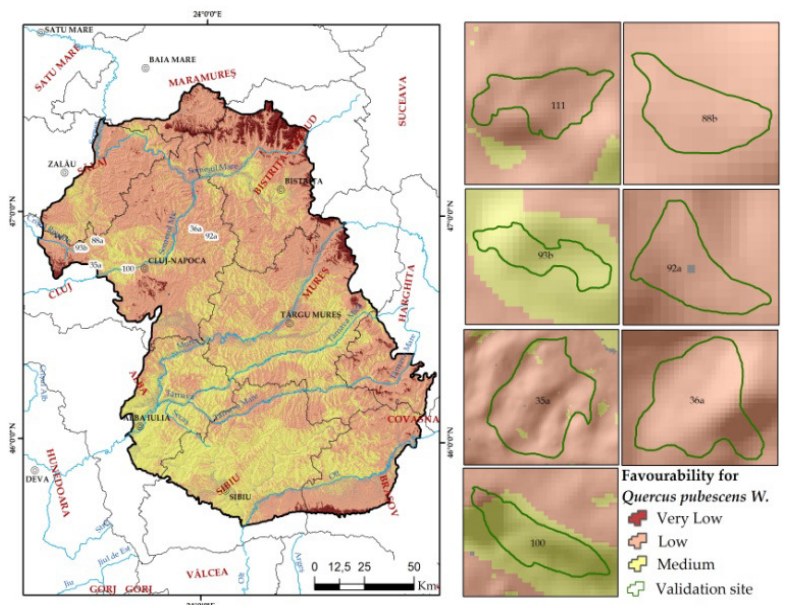

Fig. 8. Favourability map for Quercus pubescens 
1306

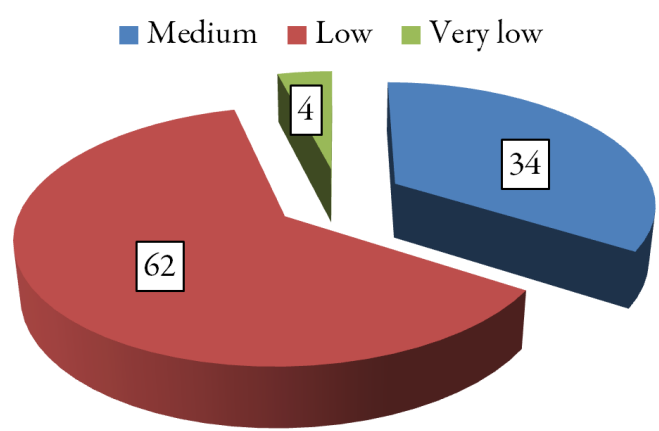

Fig. 9. Weighted distribution of favourability classes (\%) in the Transylvanian Basin

\section{Conclusions}

Synthesizing, the present study proposes a GIS model of spatial analysis performed according to spatial databases representing favourable and restrictive factors for the species Quercus pubescens, their integration and spatial analysis equations having the main goal the identification of favourable and restrictive areas for the mentioned species across the entire Transylvanian Basin. The used databases have materialized as a unitary format in the 14 determining ecological factors regarding Quercus pubescens.

The high validation rate of the proposed model indicates its high degree of predictability for the analyzed territory, so that the results achieved may be applied in practice and analyzed as such. Based on the analysis of the final results, it comes out that the medium favourability class covers a large area. Within the study area, this favourability class may be correlated with the variation of temperature and precipitation, which highlights their influence in the final result and the impact of general climate changes regarding the distribution of woodland species within the analyzed territory, as well as the acclimatization of new species across large areas in the Transylvanian Basin. At the same, the correlations highlight the restrictive character of the soil and morphological factors in terms of the distribution of Quercus pubescens favourability classes in the study area, a fact mainly caused by the low level of useful water capacity in the soil, corroborated with the soil base saturation and soil acidity.

The medium favourability class for downy oak (Quercus pubescens) in the analysed area is extended over Sibiu, Mures and Alba counties, which cover large areas of the Transylvanian Basin. The favourable areas have been identified in the region of high hills and at the contact between the hills and the surrounding mountains, where the environmental conditions related to the climatic factors are not restrictive for Quercus pubescens, highlighting once again their importance for the analyzed species. At the other end one finds the counties of Maramureș, Bistrița-Năsăud and Mures, which is explained by their territorial extension in the mountain areas neighbouring the analyzed region, where the temperatures and precipitation are unfavourable. In the case of Mures, County, one should also take into account the presence of the Transylvanian Plain and the low hills, where the soil conditions are restrictive.

\section{Acknowledgements}

The present work has received financial support through the project: Entrepreneurship for innovation through doctoral and postdoctoral research, POCU/360/ 6/13/123886 co-financed by the European Social Fund, through the Operational Program for Human Capital 2014-2020. All authors have an equal contribution to this paper.

\section{Conflict of Interest}

The authors declare that there are no conflicts of interest related to this article.

\section{References}

Arend M, Kuster T, Günthardt-Goerg MS, Dobbertin M (2011). Provenance-specific growth responses to drought and air warming in three European oak species (Quercus robur, Q.petraea and Q.pubescens). Tree Physiology 31(3):287-297.

Bobiec A, Reif A, Öllerer K (2018). Seeing the oakscape beyond the forest: a landscape approach to the oak regeneration in Europe. Landscape Ecology33(4):512-528.

Breda N, Huc R, Granier A, Dreyer E (2006). Temperate forest trees and stands under severe drought: a review of ecophysiological responses, adaptation processes and long-term consequences. Annals of Forest Science 63(6):625-644.

Doniță N, Chiriță C, Roşu C (1981). Formațiile forestiere şi condițiile lor de viață. In: Pădurile României [Forest formations and their living conditions. In: Romanian Forests]. Romanian Academy Press, Romania, Bucharest.

Ducousso A, Bordacs S (2003). EUFORGEN, technical guidelines for genetic conservation and use for pedunculated and sessile oaks (Quercus robur/Quercuspetraea). Conference Rome, Bioversity pp 6.

Dumitru M, DumitruS, Tănase V, Mocanu V, Manea A, Vrînceanu N, ... Calciu I (2011). Monitoringul stării de calitate a solurilor din România [Monitoring of soil quality in Romania]. Craiova, SITECH Publishing.

Florență G (2015). Biological particularities of the Downy oak (Quercus pubescens Willd) in Moldova. $\mathrm{PhD}$ Thesis, Academy of Sciences of Moldova, Chişinău.

Furtună P (2017). Temporal and spatial variation of forest coverage in Apuseni Natural Park, 2000-2014 period. Geographia Technica 12(1):46-56.

Galiano L, Martínez-VilaltaJ,Eugenio M, Granzow-DeLa Cerda I, Lloret F (2013). Seedling emergence and growth of Quercus spp. following severe drought effects on a Pinus sylvestris canopy. Journal of Vegetation Science 24:580-588.

Guettouche MS, Derias A (2013). Modelling of environment vulnerability to forests fires and assessment by GIS application on the forests of Djelfa (Algeria).Journal of Geographic Information System 5(1):2432.

Lacaze B, Tarabant F, Rambal T (1996). Adaptation and local validation in a Mediterranean environment of a process-level ecosystem model driven by remotely sensed inputs. In: Remote sensing ' 96 integrated applications for risk assessment and disaster prevention for the 
Mediterranean pp 299-304.

LoidiJ,Herrera M(1990). The Quercuspubescens and Quercusfaginea forests in the Basque Country (Spain): distribution and typology in relation to climatic factors. Vegetatio 90(1):81-92.

Mîndru M, Roșca S, Bilașco Șt, Păcurar I, Fodorean I, Vescan I, ... Breje M (2018). The monitoring of greenery coverage levels according to the remote sensingindices in the the Mociar Forest. Geographia Napocensis $\mathrm{XII}(1): 27-34$.

Păcurar I, Bilaşco Ş, Cristina CM, Dirja M, Moldovan I, Păcurar H, Lucaci $\mathrm{Al}$ (2013). Research on identification of degraded land in Transylvanian Plateau using GIS spatial analysis. ProEnvironment 6(14):216-227.

Pasta S, de Rigo D, Caudullo G (2016). Quercus pubescens in Europe: distribution, habitat, usage and threats. In: European Atlas of Forest Tree Speciespp 156-157.

Reif A, Xystrakis F, Gartner S, Sayer U (2017). Floristic change at the drought limit of European beech (Fagus sylvatica L.) to downy oak (Quercus pubescens) forest in the temperate climate of central Europe. Notulae Botanicae Horti Agrobotanici Cluj-Napoca 45(2):646-654.
RørstadP, Trømborg, E, BergsengE, SolbergB (2010). Combining GIS and forest modelling in estimating regional supply of harvest residues in Norway.Silva Fennica 44(3):435-451.

Roșca S, Bilașco S, Păcurar I, Colniță D, Fodorean I, Vescan I, ... Păcurar H (2017). Quantitative evaluation of forest favourability using GIS database in a hill area in the Transylvania Depression, Romania. Geomatics, Natural Hazards and Risk 8(2):19141934.

Roșca S, Simonca V, Bilasco S, Vescan I, Fodorean, I, Petrea D (2019). The assessment of favourability and spatio-temporal dynamics of Pinus mugo in the Romanian Carpathians using GIS technology and landsat images. Sustainability 11(13):3678.

Stănescu V (1979). Dendrologie [Dendrology]. Editura Didactică şi Pedagogică, București.

Wellstein C, Cianfaglione K (2012). Impact of extreme drought and warming on survival and growth characteristics of different provenances of juvenile Quercuspubescens willd. Folia Geobotanica 49(1):31-47. 